\title{
NÍVEIS DE CONCENTRADO E FARELO DO MESOCARPO DE BABAÇU SOBRE AS CARACTERÍSTICAS DA CARCAÇA DE TOURINHOS CONFINADOS
}

\author{
CONCENTRATE LEVELS AND BABASSU MESOCARP BRAN ON CARCASS \\ CHARACTERISTICS OF FEEDLOT BULLS
}

\begin{abstract}
Rossini Sôffa da CRUZ1 ${ }^{1}$ Emerson ALEXANDRINO² Regis Luis MISSIO $^{3}$; João RESTLE ${ }^{4}$; Jonahtan Chaves MELO ${ }^{1}$; Joaquim José de Paula NETO ${ }^{5}$; André Augusto Marinho SILVA ${ }^{6}$; Darlene Pereira da SILVA

1. Zootecnista, Msc., Doutorando em Ciência Animal Tropical, Fundação Universidade Federal do Tocantins UFT, Araguaína, TO, Brasil; 2. Zootecnista, Professor, Doutor, UFT, Araguaína, TO, Brasil; 3. Zootecnista, Msc., Dsc., Pós-doutorando em Ciência animal Tropical, UFT, Araguaína, TO, Brasil. regisluismissio@gmail.com; 4. Engenheiro Agrônomo, PhD., Bolsista PVNS-Capes, UFT, Araguaína, TO, Brasil; 5. Zootecnista, mestrando em Ciência Animal Tropical, UFT, Araguaína, TO, Brasil; 6. Graduando em Zootecnia, UFT, Araguaína, TO, Brasil.
\end{abstract}

\begin{abstract}
RESUMO: Objetivou-se avaliar as características da carcaça de tourinhos alimentados em confinamento com níveis de concentrado (65 e 71\%) associados ou não à inclusão de $35 \%$ de farelo do mesocarpo de babaçu (FMB) na fração

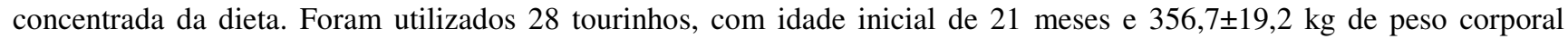
inicial. O delineamento experimental utilizado foi o inteiramente casualizado com os tratamentos em arranjado fatorial $2 \times 2$. Os pesos de carcaça quente e fria não foram alterados pelo nível de concentrado da dieta e pela inclusão do FMB no concentrado, apresentando valores médios de 256,39 e $245,87 \mathrm{~kg}$, respectivamente. Os rendimentos de carcaça quente e carcaça fria foram menores para as dietas que associaram o menor nível de concentrado e 35\% de FMB na fração concentrada da dieta. A espessura de gordura subcutânea, a conformação e a maturidade fisiológica da carcaça não foram alteradas pelo nível de concentrado e pela inclusão do FMB, com valores médios de 3,6 mm, 10,89 e 12,93 pontos, respectivamente. A inclusão de $35 \%$ de FMB no concentrado associado aos diferentes níveis de concentrados não alteraram o peso dos cortes comerciais. A inclusão de $35 \%$ de farelo do mesocarpo de babaçu na fração concentrada de dietas com elevada proporção de concentrado para tourinhos confinados não altera as principais características da carcaça de interesse econômico, proporcionando produção de carcaça com adequada qualidade.
\end{abstract}

PALAVRAS-CHAVE: Cortes comerciais. Espessura de gordura subcutânea. Longissimus dorsi.

\section{INTRODUÇÃOO}

O Brasil apresenta o maior rebanho comercial de bovinos do mundo e, ao contrário dos tradicionais países produtores, apresenta reais chances de aumento da produção, seja pelo aumento de produtividade e/ou expansão do efetivo bovino. Apesar disso, o Brasil é o terceiro produtor de equivalente carcaça, atrás dos Estados Unidos e União Europeia (ANUALPEC, 2010), reflexo do sistema de produção, o qual se caracteriza pela baixa eficiência reprodutiva e produtiva, decorrente do inadequado manejo reprodutivo, nutricional e sanitário.

A busca por melhorias na produção passa pela intensificação da atividade pecuária, sendo o confinamento uma alternativa interessante, em função de a nutrição ser à base de forragens conservadas e grãos, possibilitando elevado desempenho animal e obtenção de bovinos prontos para o abate no período de menor oferta e alta de preços. Entretanto, devido à alta no preço dos grãos, a lucratividade em confinamento tem sido prejudicada, devendo-se priorizar a redução do custo com alimentação, já que esse item pode representar 70\% do custo total (PACHECO et al., 2006a).

Com intuito de diminuir os custos no confinamento tem se pesquisado produtos alternativos ao milho, visto que sua demanda tem sido aumentada em virtude da produção de biocombustíveis. A utilização de subprodutos para substituir total ou parcialmente o milho da dieta pode representar avanços no sentido de viabilizar a utilização do confinamento. Além disso, essa interface indústria e produção animal atende as exigências de mercado, pois proporciona adequado destino aos subprodutos da indústria e aumento da produção de carne por hectare.

Por outro lado, o aporte nutricional imposto aos animais determina diferenças entre as carcaças produzidas (BRONDANI et al., 2006; MISSIO et al., 2010), sendo a densidade energética das dietas e os produtos da digestão determinantes sobre a deposição dos tecidos corporais, especialmente sobre a quantidade e o tipo de gordura depositada 
(PETHICK; HARPER; ODDY, 2004). Assim, tornam-se importantes estudos que avaliem a interação entre subprodutos e o nível energético, o qual pode ser manipulado pelo nível de concentrado da dieta. Dessa forma, objetivou avaliar as características da carcaça de tourinhos alimentados em confinamento com níveis de concentrado associados ou não à inclusão de farelo do mesocarpo de babaçu.

\section{MATERIAL E MÉTODOS}

O trabalho foi desenvolvido entre 30 de junho e 21 de setembro de 2010, na Escola de Medicina Veterinária e Zootecnia da Universidade Federal do Tocantins, Campus Araguaína, localizada a $07^{\circ} 11^{\prime} 28^{\prime \prime}$ 'de Latitude Sul e $48^{\circ} 12^{\prime} 26^{\prime \prime}$ de Longitude Oeste. Utilizaram-se 28 tourinhos da raça Nelore desmamados aos sete meses de idade com peso médio de $170 \pm 20 \mathrm{~kg}$ e recriados em pastagem de Brachiaria brizantha cv. Marandu com suplementação mineral, apresentando ao início do experimento 21 meses de idade e 356,66 $\pm 19,25 \mathrm{~kg}$ de peso corporal. Esses foram confinados em baias individuais $\left(\begin{array}{ll}14 & \mathrm{~m}^{2}\end{array}\right)$ parcialmente cobertas, concretadas, dotadas de bebedouros e comedouros individualizados, sendo pré-adaptados por 15 dias ao nível de inclusão de concentrado na dieta e ao manejo de alimentação. Após, os animais foram distribuídos nas dietas experimentais (Tabela 1), sendo adaptados às instalações por sete dias. As dietas foram formuladas para serem isoproteicas (12,3\%), considerando consumo de $2,4 \%$ do peso corporal (NRC, 1996) e proporção de volumoso segundo o nível de concentrado desejado.

Tabela 1. Composição centesimal e bromatológicas das dietas experimentais.

Dietas

Ingredientes, \% da MS

65C/0FMB 71C/0FMB 65C/35FMB 71C/35FMB

\begin{tabular}{|c|c|c|c|c|}
\hline Silagem de Brachiaria brizanta cv. Piatã & 35,00 & 29,00 & 35,00 & 29,00 \\
\hline Farelo de mesocarpo do babaçu & -- & -- & 22,68 & 25,46 \\
\hline Grão de milho moído & 54,97 & 62,80 & 32,46 & 36,74 \\
\hline Farelo de soja & 7,49 & 5,80 & 6,67 & 5,70 \\
\hline Uréia pecuária & 0,91 & 0,88 & 1,51 & 1,50 \\
\hline Calcário calcítico & 0,82 & 0,78 & 0,81 & 0,77 \\
\hline Núcleo mineral ${ }^{1}$ & 0,51 & 0,44 & 0,51 & 0,48 \\
\hline Sal comum & 0,21 & 0,20 & 0,20 & 0,19 \\
\hline Sulfato de amônio & 0,09 & 0,10 & 0,17 & 0,17 \\
\hline Matéria seca ${ }^{2}$ & 70,00 & 72,67 & 70,10 & 72,80 \\
\hline Proteína bruta & 12,46 & 12,00 & 12,58 & 12,24 \\
\hline Fibra em detergente neutro ${ }^{3}$ & 28,43 & 24,86 & 32,88 & 29,85 \\
\hline Nutrientes digestíveis totais & 73,84 & 76,04 & 67,33 & 68,69 \\
\hline
\end{tabular}

$65 \mathrm{C}$ e $71 \mathrm{C}=65$ e $71 \%$ de concentrado na dieta e, $0 \mathrm{FMB}$ e $35 \mathrm{FMB}=0$ e $35 \%$ de farelo do mesocarpo de babaçu no concentrado; ${ }^{1}$ Composição $(\mathrm{g} / \mathrm{kg})=\mathrm{Na}: 150$, Ca: 118, P: 90, Mg: 7, S: 12, N: 10, Zn: 3,6, Cu: 1,73, Co: 0,2, Mn: 0,1, I: 0,015, Se: 0,002; ${ }^{2} \%$ da matéria natural; ${ }^{3}$ corrigida para cinzas e proteínas. 
A oferta de alimento foi mantida em $10 \%$ acima do consumo voluntário, sendo ajustada diariamente pela pesagem das sobras do dia anterior, fornecida em duas refeições diárias (08 e 14 horas), com mistura do volumoso e concentrado no cocho. $\mathrm{O}$ volumoso utilizado foi à silagem de Brachiaria brizantha cv. Piatã, cortada em fase inicial de florescimento, apresentando tamanho de partícula entre 2 e $3 \mathrm{~cm}$ e teores de matéria seca (MS), proteína bruta $(\mathrm{PB})$, fibra em detergente neutro (FDN) e nutrientes digestíveis totais (NDT) de 40,0; 5,6; 28,4 e 56,0, respectivamente. O farelo do mesocarpo de babaçu (FMB) foi obtido comercialmente, apresentando teores de MS, PB, FDN e NDT de, respectivamente, 85,5; 3,2; 31,6 e $61,5 \%$.

Para determinação da composição química das dietas foram coletadas amostras dos alimentos semanalmente, as quais foram embaladas, identificadas e congeladas a $-20^{\circ} \mathrm{C}$. Após o término do experimento, as amostras foram descongeladas e realizou-se amostragem composta por período. Essas amostras foram pré-secas em estufa de ar forçado à $55^{\circ} \mathrm{C}$ por 72 horas e processadas em moinho de facas para tamanho de partícula de 1 $\mathrm{mm}$. Os teores matéria seca (MS) e proteína bruta (PB) foram determinados segundo AOAC (1995). O teor de fibra em detergente neutro (FDN) foi determinada segundo Van Soest et al. (1991), sendo a FDN corrigida para cinzas e proteínas (FDNcp). O teor de nutrientes digestíveis totais (NDT) foi determinado segundo Sniffen et al. (1992) onde: consumo de NDT $=$ CHT ingerido - CHT fezes + PB ingerida $-\mathrm{PB}$ fezes $+2,25^{*}$ EE ing. - EE fezes) e NDT $\%$ = Consumo de NDT/Consumo de MS.

Os animais foram abatidos em frigorífico comercial com fiscalização do SIF, após jejum de sólidos e líquidos de 14 horas, ao atingirem peso mínimo exigido pelos frigoríficos da região (460 $\mathrm{kg}$ ), o que ocorreu após 77 dias de confinamento. Após o abate, as carcaças foram identificadas, divididas ao meio, pesadas, lavadas e levadas ao resfriamento por 24 horas em temperatura variando entre 0 e $2^{\circ} \mathrm{C}$. Após o resfriamento, as carcaças foram pesadas e avaliadas quanto à conformação e maturidade fisiológica segundo metodologia descrita por Müller (1987). O rendimento de carcaça foi obtido pela relação entre o peso de carcaça e o peso de fazenda.

Na meia-carcaça direita foram realizadas as medidas métricas: comprimento de carcaça (do bordo anterior do osso púbis ao bordo anterior medial da primeira costela), espessura de coxão (medida entre a face lateral e a medial da porção superior do coxão), comprimento de perna (desde a articulação tíbio-tarsiana até o bordo anterior do púbis), comprimento de braço (da articulação rádiocarpiana até a extremidade do olecrano) e perímetro de braço (envolvendo a parte média do rádio-cúbito e os músculos que recobrem a região). Nessa meia carcaça, realizou-se um corte entre a 12 e $13^{\mathrm{a}}$ costelas, expondo-se o músculo Longissimus dorsi, onde foi determinada a área desse músculo e a espessura de gordura subcutânea (média aritmética de três observações). Na meia-carcaça esquerda, o dianteiro foi separado do traseiro e o costilhar entre a $5^{\mathrm{a}}$ e $6^{\mathrm{a}}$ costela, incluindo pescoço, paleta, braço e cinco costelas. $\mathrm{O}$ traseiro foi separado do costilhar a $22 \mathrm{~cm}$ da coluna vertebral e, o costilhar incluindo as costelas a partir da sexta, mais os músculos abdominais. Depois de separados, os cortes foram pesados, determinando-se o peso relativo à meiacarcaça.

$\mathrm{O}$ delineamento experimental foi $\mathrm{O}$ inteiramente casualizado com os tratamentos em arranjo fatorial $2 \times 2$ (dois níveis de concentrado e dois níveis de inclusão do farelo do mesocarpo do babaçu), utilizando-se sete repetições. Os dados foram submetidos à análise de variância e correlação de Pearson. $\mathrm{O}$ modelo matemático foi representado por: $\gamma_{\mathrm{ij}}=\mu+\tau_{\mathrm{i}}+£_{\mathrm{j}}+\tau_{\mathrm{i}} * £_{\mathrm{j}}+\varepsilon_{\mathrm{ij}}$, onde: $\gamma_{\mathrm{ij}}=$ variável dependente; $\mu=$ média geral; $\tau_{\mathrm{i}}=$ efeito do fator i (nível de concentrado); $£_{\mathrm{j}}=$ efeito do fator $(\mathrm{FMB}) ;\left(\tau_{\mathrm{i}}^{*} £_{\mathrm{j}}\right)=$ interação entre fator i e fator $\mathrm{j} ; \varepsilon_{\mathrm{ij}}=$ erro experimental residual.

\section{RESULTADOS E DISCUSSÃO}

O peso de abate, o peso de carcaça quente e fria não foram alterados $(\mathrm{P}>0,05)$ pelo nível de concentrado e farelo do mesocarpo do babaçu (FMB) (Tabela 2). Esses resultados refletiram o similar desenvolvimento corporal dos animais durante o período de terminação (CRUZ, 2012), como resultado do consumo de nutrientes, especialmente do similar consumo de energia digestível (CRUZ et al. 2012). Contribuíram para esses resultados os similares pesos de abate, visto que o peso de carcaça é determinado pelo peso de abate e pelo rendimento de carcaça (KUSS et al., 2005). Neste estudo, o peso de carcaça fria apresentou correlação de $\mathrm{r}=0,86(\mathrm{P}<0,0001)$ com o peso de abate, o que justifica, em grande parte, os resultados obtidos. Corroborando, Petit; Vieira e Yu (1994) afirmaram que diferenças nas características da carcaça de bovinos são raras, quando os animais são abatidos com mesmo peso corporal. 
Níveis de concentrado...

CRUZ, R. S. et al.

Tabela 2. Variáveis relacionadas com o peso e rendimento de carcaça de acordo com o nível de inclusão do farelo do mesocarpo do babaçu e o nível de concentrado na dieta

Nível de concentrado, \%

FMB no concentrado, \% (\% na MS)

$65 \quad 71$ Média

$\mathrm{CV}(\%)$

\begin{tabular}{lcccc}
\hline & Peso de abate, $\mathrm{kg}$ & & \\
0 & 460,07 & 468,35 & 464,21 & \\
35 & 469,57 & 462,35 & 465,96 & 4,89 \\
Média & 464,82 & 465,35 & 465,10
\end{tabular}

\begin{tabular}{|c|c|c|c|c|}
\hline \multicolumn{5}{|c|}{ Peso de carcaça quente, $\mathrm{kg}$} \\
\hline 0 & 258,50 & 258,07 & 258,28 & \\
\hline 35 & 252,57 & 256,43 & 254,50 & 5,66 \\
\hline Média & 255,54 & 257,25 & 256,39 & \\
\hline \multicolumn{5}{|c|}{ Peso de carcaça fria, kg } \\
\hline 0 & 247,62 & 247,88 & 247,75 & \\
\hline 35 & 242,28 & 245,6 & 243,98 & 5,55 \\
\hline Média & 244,95 & 246,78 & 245,87 & \\
\hline
\end{tabular}

Rendimento de carcaça quente, $\%$ do peso corporal*

\begin{tabular}{|c|c|c|c|c|}
\hline 0 & $56,17^{\text {Aa }}$ & $55,10^{\text {Aa }}$ & 55,63 & \\
\hline 35 & $53,79^{\mathrm{Bb}}$ & $55,46^{\mathrm{Aa}}$ & 54,63 & 2,39 \\
\hline Média & 54,98 & 55,27 & 55,13 & \\
\hline
\end{tabular}

Rendimento de carcaça fria, $\%$ do peso corporal*

\begin{tabular}{|c|c|c|c|c|}
\hline 0 & $53,80^{\text {Aa }}$ & $52,92^{\mathrm{Aa}}$ & 55,63 & \\
\hline 35 & $51,61^{\mathrm{Bb}}$ & $53,13^{\mathrm{Aa}}$ & 54,63 & 2,26 \\
\hline Média & 52,71 & 53,03 & 52,87 & \\
\hline
\end{tabular}

Médias seguidas de letras distintas (maiúsculas na coluna e minúsculas na linha) diferem $(\mathrm{P}<0,05)$ pelo teste Tukey. *Interação significativa entre fatores avaliados.

Os resultados do presente estudo foram discrepantes dos obtidos por Miotto et al. (2012), o qual verificou redução do peso de carcaça quente e fria em bovinos alimentados com níveis crescentes de farelo do mesocarpo de babaçu $(0 ; 25 ; 50 ; 75$ e $100 \%$ ) em substituição ao milho da dieta, resultado da diminuição da digestibilidade e aporte energético das dietas. Neste estudo a inclusão do FMB não determinou queda acentuada do teor energético das dietas, devido o moderado nível de inclusão do FMB, sua associação com os altos teores de concentrado das dietas (Tabela 1) e pelo ajuste do 
consumo de energia pelo animal (CRUZ et al., 2012). De outra maneira, os resultados obtidos discordaram daqueles apresentados por Silva et al. (2002) e Missio et al. (2010), os quais verificaram elevação do peso de carcaça com o avanço do nível de concentrado das dietas. Isso é decorrente do aumento do depósito de tecidos na carcaça (principalmente gordura), como resultado da elevação da taxa de ganho de peso, que reflete por sua vez, o maior consumo de energia (PETHICK; HARPER; ODDY, 2004). Neste estudo, isso não ocorreu, pois a diferença no aporte nutricional, do menor para o maior nível de concentrado, não foi suficiente para determinar acréscimo no consumo de energia digestível (CRUZ et al., 2012), determinando semelhante taxa de ganho de peso entre dietas (CRUZ, 2012), o que resultou em similares pesos de abate e de carcaça.

Considerando que a comercialização entre produtores e indústria é realizada via peso de carcaça, os resultados obtidos possibilitam presumir que a inclusão de até 35\% de FMB em dietas com elevado teor de concentrado não deprime a receita da comercialização das carcaças. Isso se torna relevante do ponto de vista econômico, visto que os subprodutos apresentam preços normalmente inferiores aos grãos comumente utilizados na alimentação animal. Tais argumentações apresentam respaldo também em outros estudos científicos (CRUZ et al., 2012; SILVA et al., 2012; MIOTTO et al., 2013), onde o FMB, apesar de apresentar menores teores de proteína bruta (entre 62,8 e $89,5 \%$ ) e energia (entre 10,4 e $30,1 \%$ ) que o grão de milho, tem possibilitado resultados satisfatórios do ponto de vista da eficiência alimentar e desempenho animal. Nesses estudos, as deficiências nutricionais do FMB têm sido superadas pela utilização de níveis mais elevados de concentrado na deita, correção do teor proteico via variação do teor de ureia e/ou alimentos proteicos, bem como pelo ajuste do comportamento ingestivo realizado pelos próprios animais.

O rendimento de carcaça (RC) foi menor $(\mathrm{P}<0,05)$ nas dietas que associaram a inclusão de FMB e o menor nível de concentrado (Tabela 2). Dentre os fatores que afetam o rendimento de carcaça, o conteúdo gastrointestinal tem sido considerado o principal fator (MENEZES et al., 2005; PACHECO et al., 2006b; PASCOAL et al., 2011), o qual contribui para redução do rendimento de carcaça, devido estimular a distensão e aumento de tamanho do retículo-rúmen (MENEZES et al., 2005; MENEZES et al., 2011; MISSIO et al., 2013). O FMB, nesse sentido, apesar de ter apresentado superior teor de fibra em detergente neutro em relação ao grão de milho (31,6\% vs 9,5\%), apresenta $96 \%$ das partículas com tamanho inferior a $1,18 \mathrm{~mm}$ (MIOTTO et al., 2013), o que não reflete efeito direto sobre o enchimento ruminal. No entanto, segundo Cruz et al. (2012), ao que tudo indica, a granulometria do FMB determina maior taxa de passagem desse alimento pelo rúmen, implicando na necessidade do animal aumentar a ingestão de alimento para manter o consumo de energia. Esse fato, associado ao teor de volumoso nas dietas que associaram a inclusão do FMB e o menor teor de concentrado possivelmente favoreceram para $o$ aumento do enchimento ruminal, acarretando assim, menor rendimento de carcaça, tal como verificado por Silva et al. (2002).

Variações no RC também têm sido atribuídas ao acabamento ocorrido pela deposição de gordura na carcaça (RESTLE; KEPLIN; VAZ, 1997), o que pode determinar, por um lado, aumento da quantidade de gordura retirada da carcaça e redução do $\mathrm{RC}$ e, por outro, devido ao reduzido acabamento de gordura, aumentar a perda de líquidos ao resfriamento (MÜLLER, 1987) e diminuir o RC. Todavia, tais argumentos não podem ser usados neste estudo, pois os animais apresentaram semelhante acabamento de gordura (Tabela 4). Por outro lado, pode-se destacar as correlações (Tabela 3 ) do rendimento de carcaça fria com a área do Longíssimus dorsi $(\mathrm{r}=0,39)$, espessura de coxão $(\mathrm{r}=0,38)$, peso de dianteiro $(\mathrm{r}=0,51)$ e de traseiro $(\mathrm{r}=0,48)$. Estas correlações, embora moderadas, demonstram que o deposito de tecidos (músculo e gordura) no dianteiro e traseiro especial foram mais efetivos para aumento do peso de carcaça do que o depósito de tecidos no ponta de agulha, tendo maior contribuição para aumento do peso de carcaça frente ao peso de abate.

A quebra ao resfriamento não foi alterada (P>0,05) pelo nível de concentrado e FMB (Tabela 4), reflexo do similar acabamento entre carcaças. Segundo Müller (1987) a gordura interfere na quebra ao resfriamento, reduzindo a perda de líquidos da carcaça. Os resultados obtidos indicam ainda similares condições na câmara fria, já que variações podem ocorrer em função de oscilações neste ambiente, como: temperatura, velocidade do vento e número de carcaças (RESTLE; KEPLIN; VAZ, 1997).

A inclusão do FMB na fração concentrada da dieta e a elevação do nível de concentrado das dietas não alteraram $(\mathrm{P}>0,05)$ a espessura de gordura subcutânea (Tabela 4), reflexo das similares taxas de ganho de peso durante o período experimental (CRUZ, 2012). 
Tabela 3. Matriz de correlação para as características da carcaça.

\begin{tabular}{|c|c|c|c|c|c|c|c|c|c|c|c|c|c|c|}
\hline & & PCQ & PCF & RCQ & RCF & QR & EGS & ALD & MF & $\mathrm{CC}$ & $\mathrm{COM}$ & EC & DI & PA \\
\hline \multirow{2}{*}{ PCF } & $\mathrm{r}$ & 0,99 & & & & & & & & & & & & \\
\hline & P & 0,0001 & & & & & & & & & & & & \\
\hline \multirow{2}{*}{ RCQ } & $\mathrm{r}$ & 0,50 & 0,48 & & & & & & & & & & & \\
\hline & $\mathrm{P}$ & 0,0062 & 0,0105 & & & & & & & & & & & \\
\hline \multirow{2}{*}{$\mathrm{RCF}$} & $\mathrm{r}$ & 0,48 & 0,48 & 0,97 & & & & & & & & & & \\
\hline & $\mathrm{P}$ & 0,0100 & 0,0102 & 0,0001 & & & & & & & & & & \\
\hline \multirow{2}{*}{ QR } & $\mathrm{r}$ & 0,21 & 0,09 & 0,32 & 0,10 & & & & & & & & & \\
\hline & $\mathrm{P}$ & 0,2774 & 0,6312 & 0,0945 & 0,6250 & & & & & & & & & \\
\hline \multirow{2}{*}{ EGS } & $\mathrm{r}$ & $-0,04$ & $-0,03$ & $-0,08$ & $-0,06$ & $-0,12$ & & & & & & & & \\
\hline & $\mathrm{P}$ & 0,8267 & 0,6312 & 0,6711 & 0,6250 & 0,5561 & & & & & & & & \\
\hline \multirow{2}{*}{ ALD } & $\mathrm{r}$ & 0,51 & 0,51 & 0,38 & 0,39 & 0,08 & $-0,20$ & & & & & & & \\
\hline & $\mathrm{P}$ & 0,0058 & 0,0057 & 0,0443 & 0,0443 & 0,7016 & 0,3173 & & & & & & & \\
\hline \multirow{2}{*}{ MF } & $\mathrm{r}$ & $-0,04$ & $-0,04$ & $-0,06$ & $-0,13$ & 0,22 & 0,23 & $-0,02$ & & & & & & \\
\hline & $\mathrm{P}$ & 0,8573 & 0,7522 & 0,4904 & 0,3138 & 0,2494 & 0,2485 & 0,9000 & & & & & & \\
\hline \multirow{2}{*}{$\mathrm{CC}$} & $r$ & $-0,05$ & $-0,05$ & $-0,06$ & $-0,04$ & $-0,10$ & 0,20 & 0,06 & 0,09 & & & & & \\
\hline & $\mathrm{P}$ & 0,7857 & 0,8306 & 0,7441 & 0,8249 & 0,6151 & 0,3011 & 0,7696 & 0,6445 & & & & & \\
\hline \multirow{2}{*}{$\mathrm{COM}$} & $\mathrm{r}$ & 0,41 & 0,41 & $-0,29$ & $-0,33$ & 0,10 & $-0,10$ & 0,15 & 0,17 & $-0,20$ & & & & \\
\hline & $\mathrm{P}$ & 0,0281 & 0,0299 & 0,1277 & 0,0830 & 0,6282 & 0,6275 & 0,4347 & 0,3735 & 0,3020 & & & & \\
\hline \multirow{2}{*}{$\mathrm{EC}$} & $\mathrm{r}$ & 0,49 & 0,48 & 0,40 & 0,39 & 0,11 & $-0,30$ & 0,29 & $-0,16$ & $-0,09$ & 0,17 & & & \\
\hline & $\mathrm{P}$ & 0,0082 & 0,0091 & 0,0353 & 0,0393 & 0,5722 & 0,1187 & 0,1363 & 0,4143 & 0,6392 & 0,3834 & & & \\
\hline \multirow{2}{*}{ DI } & $\mathrm{r}$ & 0,94 & 0,94 & 0,53 & 0,51 & 0,18 & $-0,03$ & 0,37 & 0,18 & 0,32 & 0,33 & 0,53 & & \\
\hline & $\mathrm{P}$ & 0,0001 & 0,0001 & 0,0038 & 0,0053 & 0,3646 & 0,8746 & 0,0524 & 0,3567 & 0,8375 & 0,0902 & 0,0040 & & \\
\hline \multirow{2}{*}{ PA } & $\mathrm{r}$ & 0,70 & 0,73 & $-0,01$ & 0,03 & $-0,20$ & 0,19 & 0,45 & $-0,05$ & 0,06 & 0,48 & 0,26 & 0,60 & \\
\hline & $\mathrm{P}$ & 0,0001 & 0,0001 & 0,9502 & 0,8612 & 0,3088 & 0,3294 & 0,0156 & 0,8125 & 0,7603 & 0,0094 & 0,1805 & 0,0008 & \\
\hline \multirow{2}{*}{ TE } & $\mathrm{r}$ & 0,92 & 0,93 & 0,48 & 0,48 & 0,08 & $-0,10$ & 0,56 & 0,07 & 0,38 & 0,38 & 0,40 & 0,77 & 0,72 \\
\hline & $\mathrm{P}$ & 0,0001 & 0,0001 & 0,0104 & 0,0095 & 0,6721 & 0,6295 & 0,0019 & 0,7083 & 0,04357 & 0,0439 & 0,0338 & 0,0001 & 0,0001 \\
\hline
\end{tabular}

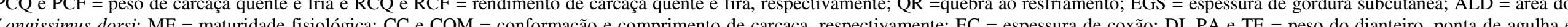
traseiro especial, respectivamente. 
Tabela 4. Variáveis referentes às características qualitativas da carcaça de acordo com o nível de inclusão do farelo do mesocarpo do babaçu (FMB) e nível de concentrado na dieta.

Nível de concentrado, \%

FMB no concentrado, \% (\% na MS)

$65 \quad 71 \quad$ Média

Quebra ao resfriamento, \%

$\begin{array}{lcccc}0 & 4,20 & 3,90 & 4,10 & \\ 35 & 4,10 & 4,20 & 4,10 & 10,81 \\ \text { Média } & 4,10 & 4,10 & 4,10 & \end{array}$

Espessura de gordura subcutânea, mm

$\begin{array}{lcccc}0 & 3,51 & 3,54 & 3,52 & \\ 35 & 3,31 & 4,03 & 3,67 & 23,34 \\ \text { Média } & 3,41 & 3,78 & 3,60 & \end{array}$

Espessura de gordura subcutânea, mm/100 kg de carcaça fria

$\begin{array}{lcccc}0 & 1,42 & 1,43 & 1,42 & \\ 35 & 1,38 & 1,64 & 1,51 & 30,55 \\ \text { Média } & 1,40 & 1,54 & 1,47 & \end{array}$

Conformação, pontos

$\begin{array}{lcccc}0 & 11,00 & 10,57 & 10,79 & \\ 35 & 10,86 & 11,14 & 11,00 & 6,34 \\ \text { Média } & 10,93 & 10,86 & 10,89 & \end{array}$

Maturidade fisiológica, pontos

\begin{tabular}{lcccc}
0 & 12,86 & 12,71 & 12,79 & \\
35 & 12,86 & 13,29 & 13,07 & 3,38 \\
Média & 12,86 & 13,00 & 12,93 & \\
\hline
\end{tabular}

$\mathrm{P}>0,05$.

A taxa de ganho de peso é o fator determinante da taxa de deposição de gordura na carcaça (NRC, 1996), embora o tipo de gordura tenha afinidade por diferentes precursores (PETHICK; HARPER; ODDY, 2004). Esses autores mencionam que em dietas com maiores precursores neoglicogênicos, ocorre maior depósito de gordura intramuscular devido sua preferência por carbonos provenientes da glicose e lactato, enquanto 
que, a gordura subcutânea tem preferencia por carbonos do acetato e unidades de acetil.

Ao se utilizar o FMB, não existem evidencias científicas que esse alimento possa alterar o perfil de metabólitos, em relação à dietas com grão de milho, a tal ponto de modificar a rota metabólica de deposição de gordura. À luz do conhecimento atual, o que se sabe, é que a utilização de baixos e médios (25 e 50\%) níveis de substituição do grão de milho pelo FMB determinam dietas com frações prontamente solúveis similares (MIOTTO, 2011), embora o tipo de amido presente nesse alimento e o local de sua digestão ainda não sejam conhecidos. Além disso, a substituição do milho por FMB reduz a fração potencialmente degradável da matéria seca e fibra em detergente neutro (MIOTTO, 2011), no entanto, o consumo de energia pode ser mantido pela adaptação do comportamento ingestivo do animal em dietas com elevado teor de concentrado (CRUZ et al., 2012). Sendo assim, o principal impacto da utilização do FMB sobre a deposição de gordura está relacionado com o aporte energético das dietas, conforme evidenciado por Miotto et al. (2012). Esses autores verificaram redução da espessura de gordura subcutânea $(\mathrm{mm} / 100 \mathrm{~kg}$ de carcaça) pelo aumento do nível de substituição do grão de milho por FMB, reflexo do decréscimo no aporte energético das dietas.

Deve-se evidenciar que a espessura de gordura de cobertura dos animais experimentais atendeu os requisitos normalmente exigidos pelos frigoríficos, mínimo de 3 e máximo de $6 \mathrm{~mm}$ (RESTLE; BRONDANI; BERNARDES, 1999), demonstrando a possibilidade de adequado acabamento de carcaça em tourinhos da raça Nelore alimentados em confinamento com elevados teores de concentrado associado à inclusão do FMB. Tais aspectos são importantes do ponto de vista do produtor, pois segundo citação de Kuss et al. (2009), a maioria dos frigoríficos da Região sul e sudeste bonificam a carcaça de animais castrados. Isso ocorre, segundo os autores, porque em carcaças de animais inteiros o acabamento normalmente é escasso, provocando escurecimento dos músculos externos durante o resfriamento, prejudicando o aspecto visual e intensificando as perdas de líquidos da carcaça, reduzindo o preço da carcaça no atacado.

A conformação e a maturidade fisiológica da carcaça não foram alteradas $(\mathrm{P}>0,05)$ pela inclusão do FMB na fração concentrada e pelo nível de concentrado das dietas (Tabela 4). Esses resultados refletiram as similares taxas de ganho de peso, o que determinou por sua vez, similar desenvolvimento corporal dos animais ao abate (CRUZ, 2011). Segundo Müller (1987), carcaças com melhor conformação são preteridas por apresentarem músculos com melhor aparência, menor proporção de osso e maior porção comestível. Destaca-se que dentre as características qualitativas (Tabela 3), apenas a conformação apresentou associação com outra variável, correlacionando-se $(\mathrm{P}<0,05)$ com o peso do traseiro especial em 0,38, demonstrando a importância do posterior para aumento do volume muscular e conformação da carcaça. Além disso, todas as carcaças avaliadas foram classificadas como "boa típica", o que é de fundamental importância para os frigoríficos, já que este segmento da cadeia produtiva busca carcaças com melhores conformações, pois tal atributo está associado com os principais cortes secundários utilizados pelos frigoríficos para formação do preço de comercialização da carcaça (PASCOAL et al., 2011).

Foi verificada interação $(\mathrm{P}<0,05)$ entre os fatores estudados para a área do Longissimus dorsi, a qual diminuiu pela inclusão do FMB no menor nível de concentrado e, pelo aumento do nível de concentrado nas dietas sem inclusão deste subproduto (Tabela 5). Quando expressa em valores relativos $\left(\mathrm{cm}^{2} / 100 \mathrm{~kg}\right.$ de carcaça fria), esta variável apresentou os menores valores para as dietas que associaram o menor nível de concentrado e 35\% de FMB no concentrado. A área do Longissimus dorsi representa informação importante, pois demonstra, principalmente, o crescimento muscular ocorrido na carcaça (MÜLLER, 1987), o que, para o presente estudo, foi evidenciado pelas correlações significativas (Tabela 3) da área do Longissimus dorsi com os pesos de carcaça quente $(\mathrm{r}=0,51)$, carcaça fria $(r=0,51)$, ponta de agulha $(r=0,45)$ e traseiro especial $(\mathrm{r}=0,56)$. No entanto, a partir das avaliações realizadas, não foi possível determinar os fatores de causa e efeito que determinaram esses resultados. Apesar disso, no que tange a aplicação desses resultados, esses podem estar indicando que a inclusão de maiores níveis de FMB em dietas para bovinos confinados, especialmente naquelas com elevadas proporções de volumoso, possam comprometer a deposição de tecidos na carcaça, podendo prejudicar o peso, bem como o acabamento de carcaça. Isso, de certa forma, foi demonstrado no estudo de Miotto et al. (2012), os quais verificaram prejuízos quanto ao peso e acabamento de carcaça para a utilização de elevados teores de FMB na dieta (75 e 100\%), embora a área do Longissimus dorsi não tenha sido alterada. 
Níveis de concentrado...

CRUZ, R. S. et al.

Tabela 5. Variáveis referentes às características métricas da carcaça de acordo com o nível de inclusão do farelo do mesocarpo do babaçu (FMB) e nível de concentrado na dieta.

Nível de concentrado, \% (\% na MS)

FMB no concentrado, $\%$

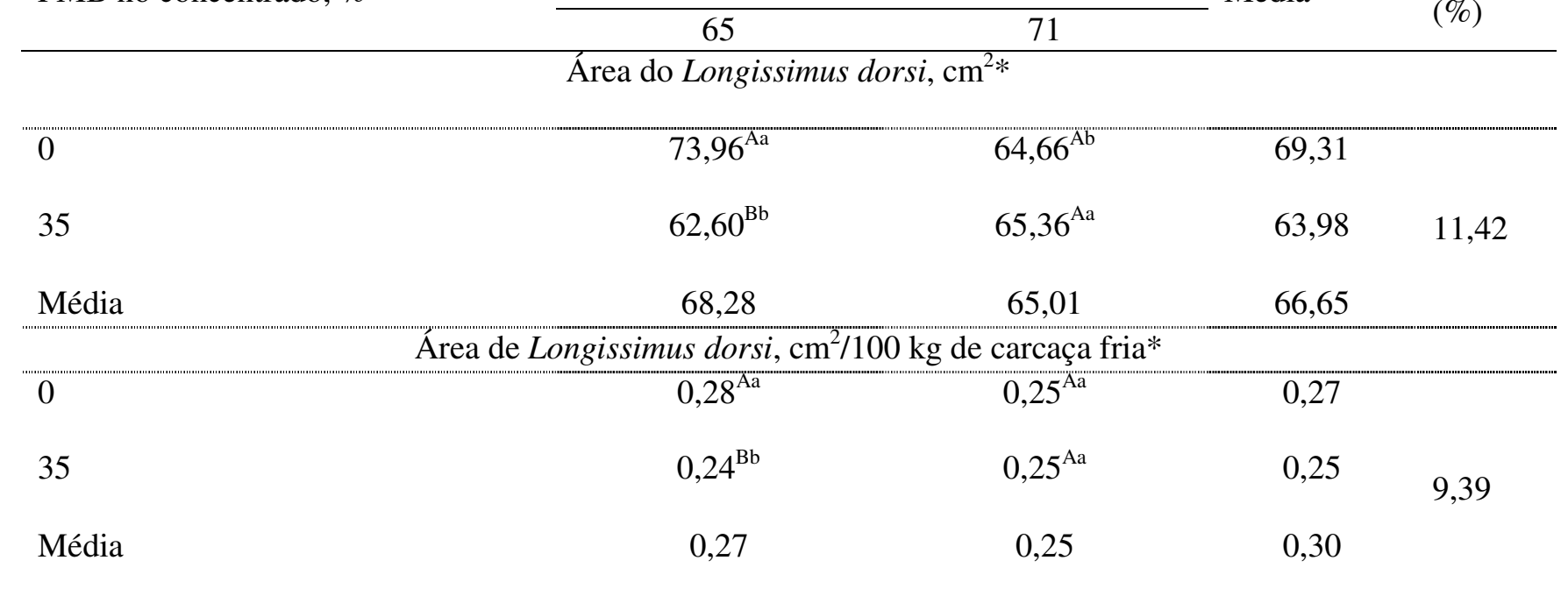

Média

CV

(\%)

Comprimento de carcaça, cm

$\begin{array}{lcccc}0 & 133,93 & 135,92 & 134,93 & \\ 35 & 137,00 & 135,07 & 136,04 & 2,69 \\ \text { Média } & 135,46 & 135,50 & 135,48 & \end{array}$

Espessura de coxão, cm

\begin{tabular}{|c|c|c|c|c|}
\hline 0 & 26,21 & 26,43 & 26,32 & \\
\hline 35 & 25,71 & 25,50 & 25,61 & 6,02 \\
\hline Média & 25,96 & 25,96 & 25,96 & \\
\hline
\end{tabular}

Comprimento de braço, cm

$\begin{array}{lcccc}0 & 42,57 & 43,21 & 42,89 & \\ 35 & 42,79 & 42,21 & 42,50 & 3,73 \\ \text { Média } & 42,67 & 42,71 & 42,70 & \end{array}$

Comprimento de perna, $\mathrm{cm}$

\begin{tabular}{|c|c|c|c|c|}
\hline 0 & 76,43 & 76,64 & $76,54^{\mathrm{A}}$ & \\
\hline 35 & 75,64 & 75,07 & $75,36^{\mathrm{B}}$ & 1,88 \\
\hline Média & 76,04 & 75,86 & 75,95 & \\
\hline
\end{tabular}

Médias seguidas de letras distintas (maiúsculas na coluna e minúsculas na linha) diferem $(\mathrm{P}<0,05)$ pelo teste Tukey. *Interação $(\mathrm{P}<0,05)$ entre os fatores avaliados. 
O comprimento de perna foi inferior $(\mathrm{P}<0,05)$ nas carcaças dos animais alimentados com FMB, não sendo alterado pelo nível de concentrado (Tabela 5). Apesar dessa diferença, as demais características métricas não foram alteradas $(\mathrm{P}>0,05)$ pelos fatores estudados, demonstrando semelhante desenvolvimento corporal dos animais. Tais resultados demonstram que a inclusão de quantidades moderadas de FMB na dieta de ruminantes não altera o desenvolvimento corporal.

$\mathrm{O}$ comprimento de carcaça apresentou $(\mathrm{P}<0,05)$ correlação de 0,48 e 0,38 com o peso de ponta de agulha e de traseiro especial (Tabela 3). Segundo citação de Kuss et al. (2005), o comprimento de carcaça pode ser aumentado pela pressão entre costelas, causada pela gordura intermuscular e intramuscular depositada nesta região, o que logicamente está relacionado com o aumento do peso do corte ponta de agulha. Já a correlação do comprimento de carcaça com o peso de traseiro especial indica que $\mathrm{o}$ crescimento muscular neste corte contribui para o aumento do comprimento de carcaça.
Os pesos dos cortes comerciais não foram alterados $(\mathrm{P}>0,05)$ pelo nível de concentrado e FMB (Tabela 6). As partes do corpo dos animais apresentam ímpetos de crescimento distintos, em que o dianteiro se desenvolve mais precocemente que o traseiro, sendo que ambos apresentam maturidade em fase anterior ao todo da carcaça, refletindo os ímpetos de crescimento dos tecidos corporais (músculo, gordura e osso) (BERG; BUTTERFIELD, 1976). O ponta de agulha é o corte cujo peso é o último a se estabilizar, pois na fase de engorda ocorre grande depósito de gordura nessa região (KUSS et al., 2005), cujo é o último tecido a ser depositado (PETHICK; HARPER; ODDY, 2004). Esses aspectos implicam que alterações nos pesos e proporções dos cortes comerciais estejam associados à diferenciação quanto ao peso corporal dos animais, como resultado de distintas taxas de crescimento e/ou idade (FOX; BLACK, 1984; BERG; BUTTERFIELD, 1979), o que não ocorreu neste estudo. Além disso, segundo Berg e Butterfield (1979), o animal tende a manter, dentro de certos limites, equilíbrio entre os quartos traseiro e dianteiro.

Tabela 6. Variáveis relacionadas com os cortes comerciais de acordo com o nível de inclusão do (FMB) e nível de concentrado na dieta.

\begin{tabular}{|c|c|c|c|c|}
\hline \multirow[b]{2}{*}{ FMB no concentrado, $\%$} & \multicolumn{2}{|c|}{ Nível de concentrado, $\%$} & \multirow[b]{2}{*}{ Média } & \multirow{2}{*}{$\begin{array}{l}\text { CV } \\
(\%)\end{array}$} \\
\hline & 65 & 71 & & \\
\hline \multicolumn{5}{|c|}{ Dianteiro, $\mathrm{kg}$} \\
\hline 0 & 50,01 & 50,37 & 50,19 & \\
\hline 35 & 49,04 & 50,16 & 49,60 & 6,74 \\
\hline Média & 49,52 & 50,26 & 49,90 & \\
\hline \multicolumn{5}{|c|}{ Dianteiro, $\%$ da carcaça fria } \\
\hline 0 & 40,37 & 40,63 & 40,50 & \\
\hline 35 & 40,48 & 40,81 & 40,65 & 2,44 \\
\hline Média & 40,42 & 40,72 & 40,57 & \\
\hline \multicolumn{5}{|c|}{ Costilhar, kg } \\
\hline 0 & 14,19 & 14,02 & 14,10 & \\
\hline 35 & 14,07 & 13,93 & 14,00 & 7,62 \\
\hline Média & 14,13 & 13,97 & 14,05 & \\
\hline
\end{tabular}


Costilhar, \% da carcaça fria

\begin{tabular}{|c|c|c|c|c|}
\hline 0 & 11,46 & 11,31 & 11,39 & \multirow{3}{*}{5,15} \\
\hline 35 & 11,61 & 11,61 & 11,47 & \\
\hline Média & 11,53 & 11,32 & 11,43 & \\
\hline \multicolumn{5}{|c|}{ Traseiro, kg } \\
\hline 0 & 59,61 & 59,55 & 59,58 & \multirow{3}{*}{2,01} \\
\hline 35 & 58,03 & 58,76 & 58,39 & \\
\hline Média & 58,82 & 59,16 & 48,00 & \\
\hline \multicolumn{5}{|c|}{ Traseiro, \% da carcaça fria } \\
\hline 0 & 48,17 & 48,05 & 48,11 & \multirow{3}{*}{5,23} \\
\hline 35 & 47,91 & 47,85 & 47,88 & \\
\hline Média & 48,04 & 47,95 & 58,99 & \\
\hline
\end{tabular}

$\mathrm{P}>0,05$.

Os cortes comerciais apresentaram elevadas correlações $(\mathrm{P}<0,05)$ entre si e com o peso de abate e de carcaça (Tabela 3), assim como verificado por Bonilha et al. (2007). Essas correlações demostraram que o peso dos cortes comerciais esteve diretamente associado ao aumento do peso corporal e, consequentemente, com o peso de carcaça.

\section{CONCLUSÃO}

A inclusão de $35 \%$ de farelo do mesocarpo de babaçu na fração concentrada de dietas com elevada proporção de concentrado para bovinos confinados não altera as principais características da carcaça de interesse econômico, podendo ser utilizado como alternativa alimentar para produção de carcaças com qualidade para a comercialização.

ABSTRACT: The objective was to evaluate the carcass characteristics of feedlot bulls fed levels of concentrate (65 and 71\%) with or without the inclusion of $35 \%$ of babassu mesocarp bran (BMB) in concentrate fraction of the diet. Twenty eight young bulls were used, with initial age of 21 month and $356.7 \pm 19.2 \mathrm{~kg}$ of initial body weight. The experimental design was completely randomized design with treatments in a factorial arrangement $2 \times 2$. Hot and cold carcass weights were not affected by dietary concentrate level and the inclusion of BMB in the concentrate, with average values of 256.39 and $245.87 \mathrm{~kg}$, respectively. Hot and cold carcass yield were lower for diets that associated the lower level of concentrate and 35\% of BMB in the concentrate fraction of the diet. Subcutaneous fat thickness, conformation and carcass physiological maturity were not affected by concentrate level and the inclusion of the BMB, averaging $3.6 \mathrm{~mm}$, 10.89 and 12.93 points respectively. The inclusion of 35\% of BMB in the concentrate associated with different levels of concentrates did not alter commercial cuts weight. The inclusion of $35 \%$ of the BMB in the concentrate fraction of diets with high concentrate for feedlot bulls does not change the carcass characteristics of economic interest, providing production of carcasses with adequate quality.

KEYWORDS: Commercial cuts. Longissimus dorsi. Subcutaneous fat thickness. 


\section{REFERÊNCIAS}

ARBOITTE, M. Z.; RESTLE, J.; ALVES FILHO, D. C.; PASCOAL, L. L.; PACHECO, P. S.; SOCCAL, D. C. Características da carcaça de novilhos 5/8 Nelore 3/8 Charolês abatidos em diferentes estádios de desenvolvimento. Revista Brasileira de Zootecnia, Viçosa, v. 33, n. 4, p. 969-977, 2004.

ASSOCIATION OF OFFICIAL ANALYTICAL CHEMISTS - AOAC. Official methods of analysis. 16.ed. Arlington: AOAC, 1995, 1025p.

ANUALPEC - Anuário da pecuária brasileira. 18.ed. São Paulo: Instituto FNP, 2010, 360p.

CRUZ, R.S. Inclusão do farelo do mesocarpo de babaçu em dietas com diferentes níveis de concentrado para bovinos alimentados em confinamento. 2012. 119f. Tese (Doutorado em Ciência Animal Tropical) Escola de Medicina Veterinária e Zootecnia, Fundação Universidade Federal do Tocantins, Araguaína. 2012.

CRUZ, R. S.; ALEXANDRINO, E.; MISSIO, R. L.; NEIVA, J. N. M.; RESTLE, J.; MELO, J. C.; JÚNIOR, A. S.; RESENDE, J. M. Feeding behaviors of feedlot bulls fed concentrate levels and babaçu mesocarp meal. Revista Brasileira de Zootecnia, Viçosa, v. 41, n. 7, p. 1727-1736, 2012.

BONILHA, S. F. M.; PACKER, I. U.; FIGUEREDO, L. A.; ALLEONI, G. F.; RESENDE, F. D.; RAZOOK, A. G. Efeitos da seleção para peso pós-desmame sobre características de carcaça e rendimento de cortes cárneos comerciais de bovinos. Revista Brasileira de Zootecnia, Viçosa, v. 36, n. 5, p. 1275-1281, 2007.

BRONDANI, I. L.; SAMPAIO, A. A. M.; RESTLE, J.; ALVES FILHO, D. C.; FREITAS, L. S.; AMARAL, G. A.; SILVEIRA, M. F.; CEZIMBRA, I. M. Composição física da carcaça e aspectos qualitativos da carne de bovinos de diferentes raças alimentados com diferentes níveis de energia. Revista Brasileira de Zootecnia, Viçosa, v. 35, n. 5, p. 2034-2042, 2006.

FOX, D. G.; BLACK, J. R. System for predicting body composition and performance of crowing cattle. Journal of Animal Science, Champaign, v. 58, n. 3, p. 725-739, 1984.

KUSS, F.; RESTLE, J.; BRONDANI, I. L.; PASCOAL, L. L.; MENEZES, F. G.; PAZDIORA, R. D.; FREITAS, L. S. Características da carcaça de vacas de descarte de diferentes grupos genéticos terminadas em confinamento com distintos pesos. Revista Brasileira de Zootecnia, Viçosa, v. 34, n. 3, p. 915-925, 2005.

KUSS, F.; LÓPEZ, J.; BARCELLOS, J. O. J.; RESTLE, J.; MOLETTA, J. L.; PERROTO, D. Características da carcaça de novilhos não-castrados ou castrados terminados em confinamento e abatidos aos 16 ou 26 meses de idade. Revista Brasileira de zootecnia, Viçosa, v. 38, n. 3, p. 515-522, 2009.

MENEZES, L. F. G.; RESTLE, J.; BRONDANI, I. L.; ALVES FILHO, D. C.; KUSS, F.; SILVEIRA, M. F.; AMARAL, G. A. Características da carcaça de novilhos de gerações avançadas do cruzamento alternado entre as raças Charolês e Nelore, terminados em confinamento. Revista Brasileira de Zootecnia, Viçosa, v. 34, n. 3 , p. 934-945, 2005.

MENEZES, L. F. G.; BRONDANI, I. L.; RESTLE, J.; ALVES FILHO, D. C.; CALLEGARO, A. M.; WEISE, M. Características dos componentes não integrantes da carcaça de novilhos super jovens da raça Devon, terminados em diferentes sistemas de alimentação. Arquivos Brasileiros de Zootecnia, Belo Horizonte, v. 63, n. 2, p. 372-381, 2011. http://dx.doi.org/10.1590/S0102-09352011000200015

MIOTTO, F. R. C. Farelo do mesocarpo de babaçu na produção de bovinos de corte. 2011. 158f. Tese (Doutorado em Zootecnia), Universidade Federal de Goiás, Goiânia. 2011.

MIOTTO, F. R. C.; RESTLE, J.; NEIVA, J. N. M.; LAGE, M. E.; CASTRO, K. J.; ALEXANDRINO. Farelo do mesocarpo de babaçu na terminação de tourinhos: características da carcaça e cortes secundários do traseiro especial. Ciência Animal Brasileira, Santa Maria, v. 13, n. 4, p. 440-449, 2012. 
MIOTTO, F. R. C.; RESTLE, J.; NEIVA, J. N. M.; CASTRO, K. J.; SOUSA, L. F.; SILVA, R. de. O. da.; FREITAS, B. B. de.; LEÃO, J. P. Replacement of corn by babassu mesocarp bran in diets for feedlot Young bulls. Revista Brasileira de Zootecnia, Viçosa, v. 42, n. 3, p. 213-219, 2013.

MISSIO, R. L.; BRONDANI, I. L.; ALVES FILHO, D. C.; RESTLE, J.; ARBOITTE, M. Z.; SEGABINAZZI, L. R. Características da carcaça e da carne de tourinhos terminados em confinamento, recebendo diferentes níveis de concentrado na dieta. Revista Brasileira Zootecnia, Viçosa, v. 39, n. 7, p. 1610-1617, 2010.

MISSIO, R. L.; RESTLE, J.; MOLETTA, J. L.; KUSS, F.; NEIVA, J. N. M.; MIOTTO, F. R. C.; PRADO, I. N.; ELEJALDE, D. A. G.; PERROTO, D. Componentes do corpo vazio de vacas da raça Purunã abatidas com pesos distintos. Semina: Ciências Agrárias, Londrina, v. 34, n. 2, p. 883-894, 2013.

MÜLLER, L. Normas para avaliação de carcaças e concurso de carcaça de novilhos. 1.ed. Santa Maria: Universidade Federal de Santa Maria, 1987. 31p.

NATIONAL RESEARCH COUNCIL - NRC. Nutrients requirements of beef cattle. 7.ed. Washington, D. C.: 1996. 242p.

PACHECO, P. S.; RESTLE, J.; VAZ, F. N.; FREITAS, A. K.; PADUA, J. T.; NEUMANN, M.; ARBOITTE, M. Z. Avaliação econômica em confinamento de novilhos jovens e super jovens de diferentes grupos genéticos. Revista Brasileira de Zootecnia, Viçosa, v. 35, n. 1, p. 309-320, 2006a.

PACHECO, P. S.; RESTLE, J.; SILVA, J. H. S.; FREITAS, A. K.; ARBOITTE, M. Z.; PADUA, J. T. Relação entre componentes do corpo vazio e rendimentos de carcaça de novilhos de corte. Revista Ciência Animal Brasileira, Goiânia, v. 7, n. 2, p. 107-113, 2006b.

PASCOAL, L. L.; VAZ, F. N.; VAZ, R. Z.; RESTLE, J.; PACHECO, P. S.; SANTOS, J. P. A. Relações comerciais entre produtor, indústria e varejo e as implicações na diferenciação e precificação de carne e produtos não-carcaça. Revista Brasileira de Zootecnia, Viçosa, v. 40, p. 82-92, 2011. Suplemento.

PETHICK, D. W.; HARPER, G. S.; ODDY, V. H. Growth, developpment and nutritional manipulation of marbling in cattle: a review. Australian Journal Experimental Agriculture, Collingwood v. 44, [s.n], p. 704715, 2004.

PETIT, H. V. ; VEIRA, D. M.; YU, Y. Growth and carcass characteristics of beef steers fed silage and different levels of energy with or without protein supplementation. Journal of Animal Science, Champaign, v. 52, n. 2, p. 3221-3229, 1994.

RESTLE, J.; KEPLIN, L. A. S.; VAZ, F. N. Características da carcaça de novilhos Charolês, abatidos com diferentes pesos. Pesquisa Agropecuária Brasileira, Brasília, v. 32, n. 8, p. 851-856, 1997.

RESTLE, J.; BRONDANI, I. L.; BERNARDES, R. A. C. O novilho super precoce. In: RESTLE, J. (Ed.). Confinamento, pastagens e suplementação para produção de bovinos de corte. Santa Maria: Universidade Federal de Santa Maria, 1999. p. 191-214.

SILVA, F. F.; VALADARES FILHO, S. C.; ÍTAVO, L. C. V.; VELOSO, C. M.; PAULINO, M. F.; VALADARES, R. F.; CECON, P. R.; SILVA, P. A.; GALVÃO, R. M. Consumo, desempenho, características de carcaça e biometria do trato gastrintestinal e dos órgãos internos de novilhos nelore recebendo dietas com diferentes níveis de concentrado e proteína. Revista Brasileira de Zootecnia, Viçosa, v. 31, n. 4, p. 1849$1864,2002$.

SILVA, N. R.; FERREIRA, A. C. H.; FATURI, C.; SILVA, G. F.; MISSIO, R. L.; NEIVA, J. N. M.; ARAÚJO, V. L.; ALEXANDRINO, E. Desempenho em confinamento de bovinos de corte, castrados ou não, 
alimentados com teores crescentes de farelo do mesocarpo de babaçu. Ciência Rural, Santa Maria, v. 42, n. 10, p. 1882-1887, 2012. http://dx.doi.org/10.1590/S0103-84782012001000027

SNIFFEN, C. J.; CONNOR, J. D. O.; VAN SOEST, P. J.; FOX, D. G.; RUSSELL, J. B. A net carbohydrate and protein system for evaluating cattle diets: II. Carbohydrate and protein availability. Journal of Animal Science, Champaign, v. 70, p. 3562-3577, 1992.

VAN SOEST, P. J. Collaborative study of acid detergent fiber and lignin. Journal of the Association of Official Analytical Chemists, Arlington, v. 56, [s.n], p. 81-784, 1973.

VAN SOEST, P. J.; ROBERTTSON, J. B.; LEWIS, B. A. Methods for dietary fiber, neutral detergent fiber, and nonstarch polysaccharides in relation to animal nutrition, Journal of Dairy Science, Madison, v. 74, n. 10, p. 3583-3597, 1991. http://dx.doi.org/10.3168/jds.S0022-0302(91)78551-2 